\title{
Effect of Nitridation and Pre-Growth Annealing of the Sapphire Substrate on the Quality of Zinc Oxide Thin Films Grown by RF-Magnetron Sputtering
}

\author{
M. BASEER HAIDER* \\ Department of Physics, King Fahd University of Petroleum and Minerals, Dhahran 31261, Saudi Arabia \\ and \\ Center of Excellence in Nanotechnology, King Fahd University of Petroleum and Minerals, \\ Dhahran 31261, Saudi Arabia \\ (Received September 22, 2016)
}

\begin{abstract}
$\mathrm{ZnO}$ has attracted much attention due to its wide bandgap $(3.2 \mathrm{eV})$ and high exciton binding energy of $60 \mathrm{meV}$. These properties make $\mathrm{ZnO}$ a highly desirable material for high frequency devices that can work in harsh environment. We have grown $\mathrm{ZnO}$ thin films at different temperatures ranging from $100^{\circ} \mathrm{C}$ to $500^{\circ} \mathrm{C}$. We have observed that surface roughness is first decreased with the increase in the growth temperature but then by further increasing the growth temperature beyond $300^{\circ} \mathrm{C}$, results in increased surface roughness of the grown samples, whereas grain size of the samples increases with the increase in the growth temperature. Crystalline quality of the films is also improved with the increase in the growth temperature but then degrades by further increase beyond $200{ }^{\circ} \mathrm{C}$. We achieved the highest Hall mobility for the $\mathrm{ZnO}$ sample grown at $200^{\circ} \mathrm{C}$. The optimum growth condition of $\mathrm{ZnO}$ thin films on sapphire (0001) in our $\mathrm{RF} / \mathrm{DC}$ magnetron-sputtering unit were achieved for the films grown at $200^{\circ} \mathrm{C}$. Subsequently, we performed pre-growth treatment to the sapphire substrate then grew $\mathrm{ZnO}$ films at $200^{\circ} \mathrm{C}$. Pre-growth treatment involved heating the substrate at $500^{\circ} \mathrm{C}$ for about half an hour and then etching the sapphire surface with nitrogen plasma. We have observed that pre-growth heating and nitridation of the sapphire substrate results in bigger grain size whereas no improvement was observed in the crystallinity of the film.
\end{abstract}

DOI: 10.12693/APhysPolA.132.1325

PACS/topics: thin films, wide bandgap semiconductors, $\mathrm{ZnO}$, magnetron sputtering

\section{Introduction}

$\mathrm{ZnO}$ has attracted much attention due to its interesting optical, electrical and piezoelectric properties. $\mathrm{ZnO}$ can potentially be used for electronic and optoelectronic applications including gas sensing, transparent conductors for touch screen windows, renewable energy, and spintronics [1-3]. $\mathrm{ZnO}$ has a band gap of $3.2 \mathrm{eV}$ and exciton binding energy of $\approx 60 \mathrm{meV}$, which is much higher than room temperature thermal energy of $\approx 25 \mathrm{meV}$ that makes it attractive material for short wavelength and transparent electronics [4-9]. ZnO also has an edge over competing wide band gap semiconductors e.g. GaN that has an exciton binding energy of only $\approx 24 \mathrm{meV}$. Moreover, both constituent elements of $\mathrm{ZnO}$ are abundantly available in nature and are environmental friendly that makes it attractive for consumer applications.

$\mathrm{ZnO}$ films have been grown at different substrates including glass, quartz, silicon and sapphire but most commonly sapphire(0001) is used as substrate to grow $\mathrm{ZnO}$ films. Intrinsically grown $\mathrm{ZnO}$ is $n$-type semiconductor due to oxygen vacancies and $\mathrm{Zn}$ interstitials $[2,10]$. The quality of the grown film can be improved by choosing appropriate substrate and pre-growth treatment of the substrate. For example, GaN has traditionally been grown on sapphire (0001) substrate but before the growth es-

\footnotetext{
*e-mail: mhaider@kfupm.edu.sa
}

pecially in MBE process, sapphire substrate is heated and nitridated before the growth of GaN film. It has been reported that pre-heating of sapphire makes sapphire surface atomically clean that results in the smooth growth of the thin film. Nitridation of sapphire surface results in the formation of thin layer of AlN [11-13]. Lattice mismatch between GaN and AlN is much smaller as compared to the mismatch between GaN and sapphire [14-16]. Therefore, nitridation of sapphire results in less stacking fault defects in GaN film and atomically smoother growth. This make pre-treatment of sapphire an essential element for GaN thin film growth.

Similar to $\mathrm{GaN}, \mathrm{ZnO}(a=3.2495 \AA)$ has also large lattice mismatch with sapphire $(a=4.758 \AA)$. This lattice mismatch results in strained layers that result in high defect densities. These defects in turn effect the crystallinity, electrical, and optical properties of the films. In order to achieve good quality smooth films and to control the properties of the $\mathrm{ZnO}$ thin film, it is important to study the effect of different growth parameters like substrate temperature and pre-treatment of the substrate on the properties of the grown $\mathrm{ZnO}$ films.

Here we report the growth of $\mathrm{ZnO}$ thin films by radio frequency magnetron sputtering on sapphire(0001) substrate at different growth conditions and found the best growth temperature that results in highly crystalline and smooth films. In the next step we grew $\mathrm{ZnO}$ films on preheated and nitridated substrate and study the effect of substrate treatment on the properties of the film. 


\section{Experiment}

$\mathrm{ZnO}$ thin films were grown in $\mathrm{RF}$ / DC magnetron sputtering unit on sapphire (0001) substrate at different growth temperatures. First, the substrates were ultrasonically cleaned for five minutes in acetone and then five minutes in isopropanol. After sonication, the substrates were left in air to dry until all the solvent was evaporated. Then the substrates were introduced into the RF/DC magnetron sputtering chamber. The chamber was evacuated to a pressure of about $1.6 \times 10^{-6}$ mbar. Ar gas (99.99\% pure) was introduced in the chamber at a flow rate of $2 \mathrm{sccm}$ (standard cubic centimeters per minute). Then RF plasma was turned on with a plasma power of $150 \mathrm{~W}$. The substrate temperature was set to desired growth temperature and was set into rotation at 6RPM for uniform film growth. The growth was started by sputtering $99.9 \%$ pure $\mathrm{ZnO}$ target. During the growth the chamber pressure was $\approx 8.5 \times 10^{-3}$ mbar. Average thickness of our $\mathrm{ZnO}$ films were about $100 \mathrm{~nm}$. We grew five samples (H1, H4, H5, H6, and H7) at 100, 200, 300, 400 , and $500^{\circ} \mathrm{C} \mathrm{C}$ respectively.

After the growth samples were taken out of the chamber and surface morphology of the samples were studied by atomic force microscopy (AFM) using non-contact or tapping mode of Veeco Innova diSPM. Crystallinity of the samples were studied by X-ray diffractometer (Shimadzu XRD-6000 diffractometer) using $\mathrm{Cu} K_{\alpha}$ radiations of wavelength $1.548 \AA$. Finally, electronic properties of the films were studied by four probe Van der Pauw method at room temperature using ECOPIA HMS 3000 Hall effect system. Another sample $\mathrm{H} 2 \mathrm{O}$ was grown on a pre-heated and nitridated sapphire (0001) substrate. Before starting the sputtering, the substrate temperature was raised to $500^{\circ} \mathrm{C}$ and kept at this temperature for about 30minutes. Then Argon and Nitrogen gases were introduced in the chamber at a flow rate of $20 \mathrm{sccm}$ and 10 sccm respectively. Finally DC etching plasma was turned on at $100 \%$ etching power for about 15 minutes. Subsequently, etching plasma was turned off and the sample temperature was brought down to the growth temperature, $\mathrm{N}_{2}$ flow was stopped and Ar flow was reduced to 2 sccm for $\mathrm{ZnO}$ thin film growth. Rest of the growth and characterization procedure is similar to what has been described above for samples H1 and H4-H7.

\section{Results and discussions}

Surface morphology, grain size and surface roughness of the grown films were studied by AFM. Shown in Fig. 1(a-e) are the AFM images of the samples (H1, H4, $\mathrm{H} 5, \mathrm{H} 6$, and $\mathrm{H} 7$ ).

AFM images shown in Fig.1 reveal that the surface morphology of all the $\mathrm{ZnO}$ films grown on sapphire substrate exhibit grain like 3D features. It is evident from the AFM images that grain size increases with the increase in the growth temperature especially when the growth temperature is above $300{ }^{\circ} \mathrm{C}$. This is because higher growth temperature results in increased energy of

\section{TABLE I}

Thin films growth temperatures, AFM surface roughness and grain size of the films from AFM images.

\begin{tabular}{c|c|c|c}
\hline \hline Sample & $\begin{array}{c}\text { Growth } \\
\text { temp. }\left[{ }^{\circ} \mathrm{C}\right]\end{array}$ & $\begin{array}{c}\text { Surface } \\
\text { rough. }[\mathrm{nm}]\end{array}$ & $\begin{array}{c}\text { Grain size } \\
(\mathrm{AFM})[\mathrm{nm}]\end{array}$ \\
\hline H1 & 100 & 9 & 8 \\
$\mathrm{H} 4$ & 200 & 3 & 7 \\
$\mathrm{H} 5$ & 300 & 3 & 9 \\
$\mathrm{H} 6$ & 400 & 7 & 12 \\
H7 & 500 & 17 & 17
\end{tabular}

species $(\mathrm{Zn}, \mathrm{O}, \mathrm{ZnO})$ that fall on the surface and have bigger diffusion length. The increased diffusion length of the new species will allow them to move around on the surface and attach to already nucleated sites, which in turn results in the bigger grain sizes. A summary of the lateral grain sizes of the samples is given in Table I.

It was observe that surface roughness first decreased with the increase in the growth temperature and then started to increase at higher growth temperatures.

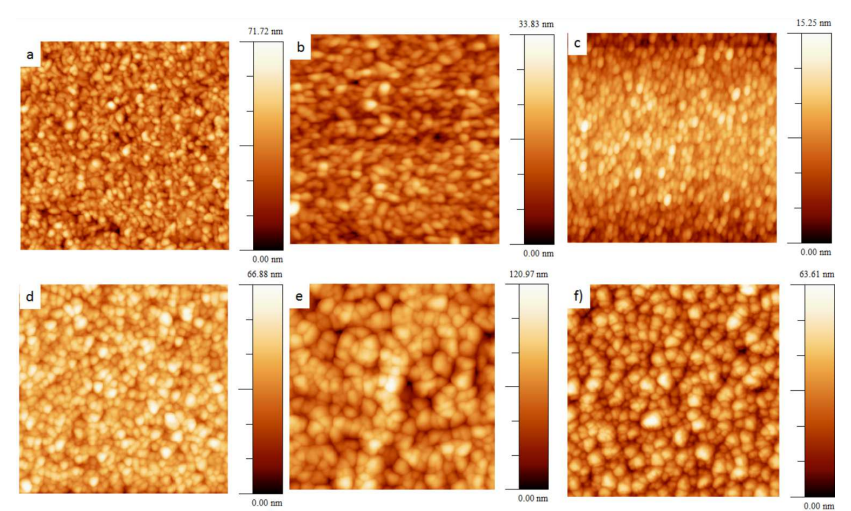

Fig. 1. AFM images of a) H1, b) H4, c) H5, d) H6, e) $\mathrm{H} 7$, and f) $\mathrm{H} 2 \mathrm{O} \mathrm{ZnO}$ films.

Show in Fig. 1(a) is the AFM image of sample H1 grown at $100^{\circ} \mathrm{C}$, this sample has an average grain size of $\approx 8 \mathrm{~nm}$ and root mean square (rms) surface roughness of about $9 \mathrm{~nm}$. Shown in Fig. 1(b) is the AFM image of sample $\mathrm{H} 4$ grown at $200^{\circ} \mathrm{C}$, that has an average grain size of about $7 \mathrm{~nm}$ and rms surface roughness of about $3 \mathrm{~nm}$. Both the grain size and rms surface roughness has been decreased compared to sample $\mathrm{H} 1$ that was grown at $100^{\circ} \mathrm{C}$. Shown in Fig 1 (c) is the AFM image of sample $\mathrm{H} 5$ grown at $300^{\circ} \mathrm{C}$, the grain size for this sample has been increased to $9 \mathrm{~nm}$ whereas there is little change in the rms surface roughness compared to sample H4. Shown in Fig. 1(d) is the AFM image of sample $\mathrm{H} 6$ grown at $400^{\circ} \mathrm{C}$, the grain size has been further increased to $12 \mathrm{~nm}$ and rms surface roughness has also been increased to $7 \mathrm{~nm}$. Shown in Fig1(e) is the AFM image of sample $\mathrm{H} 7$ grown at $500^{\circ} \mathrm{C}$. The surface morphology of $\mathrm{H} 7$ is quite different from the previous samples; here both rms surface roughness and grain size have been in- 
creased. RMS roughness of $\mathrm{H} 7$ surface is about $17 \mathrm{~nm}$ and average grain size is about $17 \mathrm{~nm}$. This indicates that at this temperature the surface diffusion length has been greatly increased resulting in the bigger grain sizes. At higher growth temperatures $\left(>300^{\circ} \mathrm{C}\right)$ the grain size is increasing that results in more three dimensional growth which leads to higher rms surface roughness. Shown in Fig. 2 are the X-ray diffraction results of the $\mathrm{ZnO}$ films. The XRD spectrum of $\mathrm{H} 1$ sample consists of a major $\mathrm{ZnO}$ (002) peak at $34.48^{\circ}$ with two small peaks at $31.82^{\circ}$ and $36.08^{\circ}$ corresponding to $\mathrm{ZnO}(100)$ and $\mathrm{ZnO}(101)$ respectively. Full width at half maximum (FWHM) of major $\mathrm{ZnO}(002)$ peak is about 0.92 degrees. The XRD spectrum of $\mathrm{H} 4$ sample is comparatively different from XRD spectrum of $\mathrm{H} 1$, it contains only $\mathrm{ZnO}(002)$ peak at $34.58^{\circ}$ with no other secondary phases present in the spectrum. Moreover, the FWHM of $\mathrm{ZnO}(002)$ peak is $0.72^{\circ}$ that is approximately $21 \%$ narrower compared to the $\mathrm{ZnO}(002)$ peak in $\mathrm{H} 1$ sample, which is an indication of better crystallinity. X-ray diffraction spectrum of H5 sample also contains only $\mathrm{ZnO}(002)$ peak at $34.64^{\circ}$ degree but the intensity of this peak is relatively smaller compared to the $\mathrm{ZnO}(002)$ peak of $\mathrm{H} 4$ sample.

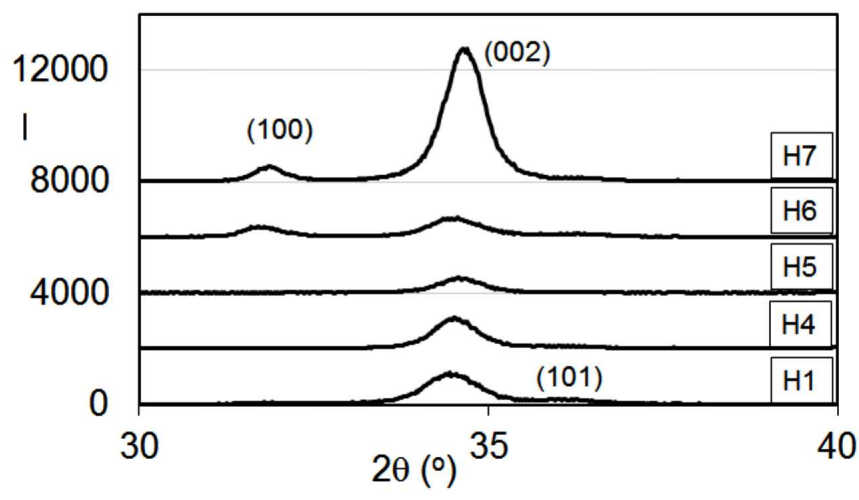

Fig. 2. XRD spectra of $\mathrm{H} 1, \mathrm{H} 4, \mathrm{H} 5, \mathrm{H} 6$ and $\mathrm{H} 7$ samples.

As well as the FWHM of $\mathrm{ZnO}(002)$ peak of $\mathrm{H} 5$ sample is $0.96^{\circ}$ which is about $33 \%$ wider compared to the corresponding peak in $\mathrm{H} 4$ sample. This indicates that $\mathrm{H} 4$ exhibits better crystallinity compared to samples $\mathrm{H} 1$ and $\mathrm{H} 5$. The XRD spectrum of $\mathrm{H} 6$ contains $\mathrm{ZnO}(002)$ peak at $34.55^{\circ}$ along with $\mathrm{ZnO}(100)$ and $\mathrm{ZnO}(101)$ peaks. The intensity of $\mathrm{ZnO}(100)$ has increased considerably as compared to sample H1. The FWHM value of the $\mathrm{ZnO}(002)$ peak for $\mathrm{H} 6$ sample is 0.88 degrees. The XRD spectrum of sample $\mathrm{H} 7$ consists of $\mathrm{ZnO}(002)$ peak at $34.7^{\circ}$ along with a strong peak at $31.8^{\circ}$ corresponding to $\mathrm{ZnO}(100)$ peak. The FWHM value of $\mathrm{ZnO}(002)$ peak is 0.7 degrees. Although FWHM of $\mathrm{ZnO}(002) \mathrm{H} 7$ is comparable to sample $\mathrm{H} 4$ but there is a strong presence of secondary phases in $\mathrm{H} 7$ sample. XRD analyses of all the samples indicate that best growth temperature of $\mathrm{ZnO}$ on sapphire for our system is $200^{\circ} \mathrm{C}$.

Hall effect measurements were performed on $\mathrm{ZnO}$ samples to investigate the carrier concentration and mobility of our samples. The carrier concentration and mobility of our samples are given in Table II. We can readily see that our samples are $n$-type and the carrier concentration of our samples increase with the increase in the growth temperature. This is expected because $n$-type characteristic of intrinsically grown $\mathrm{ZnO}$ samples is attributed to oxygen vacancies and $\mathrm{Zn}$ interstitials $[2,10]$ It is expected that more oxygen atoms/molecules would desorb from the film at higher growth temperatures.

Some of the samples (H1, H4, H5) show p-type carrier concentration, we believe this is erroneous because it has been reported that less conductive or insulating samples give erroneous results for Hall effect or Van der Pauw measurements [19]. We achieve the best thin film growth with single phase and good crystallinity and the highest mobility at a growth temperature of $200^{\circ} \mathrm{C}$.

TABLE II

Hall effect data of $\mathrm{ZnO}$ films.

\begin{tabular}{c|c|c|c|c}
\hline \hline Sample & $\begin{array}{c}\text { Growth } \\
\text { temp. }\left[{ }^{\circ} \mathrm{C}\right]\end{array}$ & $\begin{array}{c}\text { Carrier } \\
\text { conc. }\left[\mathrm{cm}^{-3}\right]\end{array}$ & $\begin{array}{c}\text { Carrier } \\
\text { type }\end{array}$ & $\begin{array}{c}\mu \\
{\left[\mathrm{cm}^{2} / \mathrm{Vs}\right]}\end{array}$ \\
\hline $\mathrm{H} 1$ & 100 & $1.9 \times 10^{13}$ & $p$-type & 50 \\
$\mathrm{H} 4$ & 200 & $1.5 \times 10^{12}$ & $p$-type & 439 \\
$\mathrm{H} 5$ & 300 & $2.9 \times 10^{12}$ & $p$-type & 23 \\
$\mathrm{H} 6$ & 400 & $2.0 \times 10^{15}$ & $n$-type & 9 \\
$\mathrm{H} 7$ & 500 & $8.8 \times 10^{16}$ & $n$-type & 2 \\
$\mathrm{H} 2 \mathrm{O}$ & 200 & $3.8 \times 10^{13}$ & $n$-type & 60
\end{tabular}

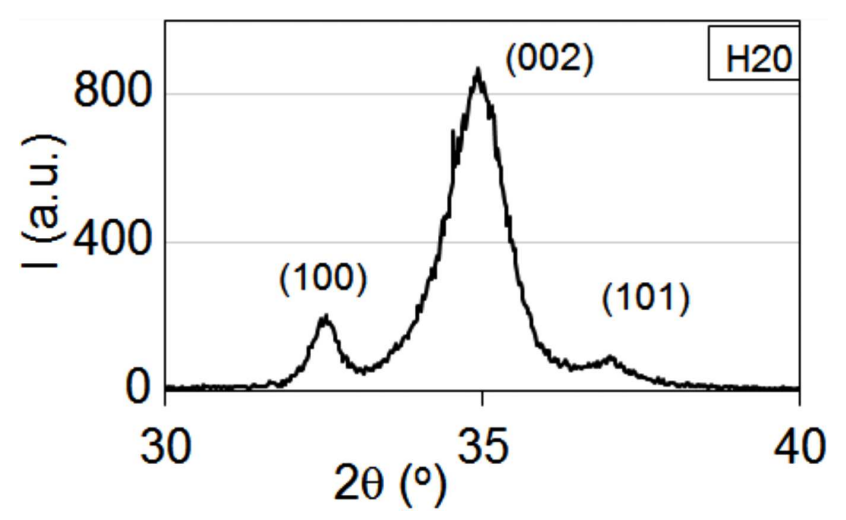

Fig. 3. XRD spectrum of $\mathrm{H}_{2} \mathrm{O} \mathrm{ZnO}$ sample grown on treated substrate.

After determining the optimal growth condition in our system, we grew another film $(\mathrm{H} 2 \mathrm{O})$ at $200^{\circ} \mathrm{C}$ but first treated the sapphire(0001) substrate by pre-heating and nitridation.

Shown in Fig.1(f) is the AFM image of the H2O sample that has an average grain size of $\approx 10 \mathrm{~nm}$ and RMS roughness of $9 \mathrm{~nm}$. This indicates that pre-heating and nitridation has resulted in considerable surface smoothness of the sapphire substrate that would result in relatively bigger grain size of $\mathrm{ZnO}$ compared to the sample grown at $200^{\circ} \mathrm{C}$ without the pre-growth treatment of the substrate. $\mathrm{ZnO}$ species deposited on a relatively 
smoother sapphire substrate would have greater diffusion length that would result in increased grain size.

Shown in Fig. 3 is the XRD spectrum of the $\mathrm{H} 2 \mathrm{O}$ sample, it can be seen that $\mathrm{ZnO}$ was grown preferably along (002) direction but still there are a couple of small peaks along (100) and (101) direction, which indicates little improvement in the crystallinity of the sample due to preheating and nitridation of the substrate. Hall effect measurements were performed and it was found that carrier concentration of the $\mathrm{H} 2 \mathrm{O}$ sample is $n$-type and is about $3.8 \times 10^{13} \mathrm{~cm}^{-3}$.

\section{Conclusion}

Zinc Oxide samples were grown at different growth temperatures ranging from $100^{\circ} \mathrm{C}$ to $500^{\circ} \mathrm{C}$ by $\mathrm{RF} / \mathrm{DC}$ magnetron sputtering. We have observed that surface roughness of the grown films is first improved with the increase in the growth temperature but then by further increasing the growth temperature beyond $300^{\circ} \mathrm{C}$ results in increased surface roughness. Whereas grain size as estimated from the AFM images increases with the increase in the growth temperatures. Crystalline quality of the films is also improved with the increase in the growth temperature but then degrades by further increasing beyond $200^{\circ} \mathrm{C}$. We achieved the highest Hall mobility for the sample grown at $200{ }^{\circ} \mathrm{C}$ that is an indication of comparatively less defects compared to the samples grown at other temperatures. The optimum growth condition of $\mathrm{ZnO}$ thin films on sapphire (0001) in our RF/DC magnetron sputtering unit were achieved for the films grown at $200^{\circ} \mathrm{C}$. Pre-growth treatment to the sapphire substrate was performed for a sample grown at $200^{\circ} \mathrm{C}$ by heating the substrate at $500{ }^{\circ} \mathrm{C}$ for about half an hour and then etching the sapphire surface with nitrogen plasma. It was observed that pre-growth heating and nitridation of the sapphire substrate resulted in larger grain size due to initial smoother substrate surface whereas no improvement was observed in the crystallinity of the film.

\section{Acknowledgments}

This work was supported by the deanship of scientific research of King Fahd University of Petroleum \& Minerals, Dahran, Saudi Arabia, through internal research grant \# IN111035.

\section{References}

[1] D.C. Look, Mater. Sci. Eng. B 80, 383 (2001).

[2] U. Ozgür, Y. Alivov, C. Liu, A. Teke, M. Reshchikov, S. Dogan, V. Avrutin, S. Cho, H. Morkoc, J. Appl. Phys. 98, 041301 (2005).

[3] S.J. Pearton, D.P. Norton, K. Ip, Y.W. Heo, T. Steiner, Superlatt. Microstruct. 34, 3 (2003).

[4] A. Mang, K. Reimann, St. Rübenacke, Solid State Commun. 94, 251 (1995).

[5] V. Srikant, D. Clarke, J. Appl. Phys. 83, 5447 (1998).

[6] D. Reynolds, D. Look, B. Jogai, C. Litton, G. Cantwell, W. Harsch, Phys. Rev. B 60, 2340 (1999).

[7] D. Bagnall, Y. Chen, Z. Zhu, T. Yao, S. Koyama, M. Shen, T. Goto, Appl. Phys. Lett. 70, 2230 (1997).

[8] D.C. Reynolds, D.C. Look, B. Jogai, Solid State Commun. 99, 873 (1996).

[9] J. Paek, K. Kim, J. Lee, D. Kim, M. Yi, D. Noh, H. Kim, S. Park, J. Cryst. Growth 200, 55 (1999).

[10] A. Janotti, C.G.V. de Walle, Rep. Prog. Phys. 72, 126501 (2009).

[11] K. Uchida, A. Watanabe, F. Yano, M. Kouguchi, T. Tanaka, S. Minagawa, J. Appl. Phys. 79, 3487 (1996).

[12] A. Yamamoto, M. Tsujino, M. Ohkubo, A. Hashimoto, J. Cryst. Growth 137, 415 (1994).

[13] H. Kawakami, K. Sakurai, K. Tsubouchi, N. Mikoshiba, Jpn. J. Appl. Phys. 27, L161 (1988).

[14] N. Grandjean, J. Massies, Y. Martinez, P. Vennegues, M. Leroux, M. Laügt, J. Cryst. Growth 178, 220 (1997).

[15] S. Keller, B.P. Kemmer, Y.-F. Wu, B. Heyring, D. Kapolnek, J.S. Speck, U.K. Mishra, S.P. Denbaars, Appl. Phys. Lett. 68, 1525 (1996).

[16] N. Grandjean, J. Massies, M. Leroux, Appl. Phys. Lett. 69, 2071 (1996). 